\title{
Transient Small-Bowel Obstruction Secondary to the Olive Tip Released During Esophageal Self- Expandable Metal Stent Placement
}

Several complications have been reported after esophageal self-expandable metal stent placement. These include stent migration, bleeding, perforation, fistula formation and occlusion [1,2]. An increased incidence of migration and bleeding has been described for stents placed across the gastroesophageal junction [3]. We present a case of transient small-bowel obstruction after esophageal stenting, caused by the delivery device for the stent.

A 64-year-old man was admitted to our hospital complaining of progressive dysphagia and weight loss. After a diagnosis of squamous cell carcinoma of the middle-lower esophagus was made he was referred to the endoscopy unit for esophageal stenting. An antireflux Dostent (MI Tech Co. Ltd., Suwon, Korea) was successfully inserted.

The Dostent is a self-expandable stent made from a single thread of nitinol wire, with inner valves and covered with a polyurethane membrane. The delivery system has an olive tip at the distal end which drops into the stomach once stent

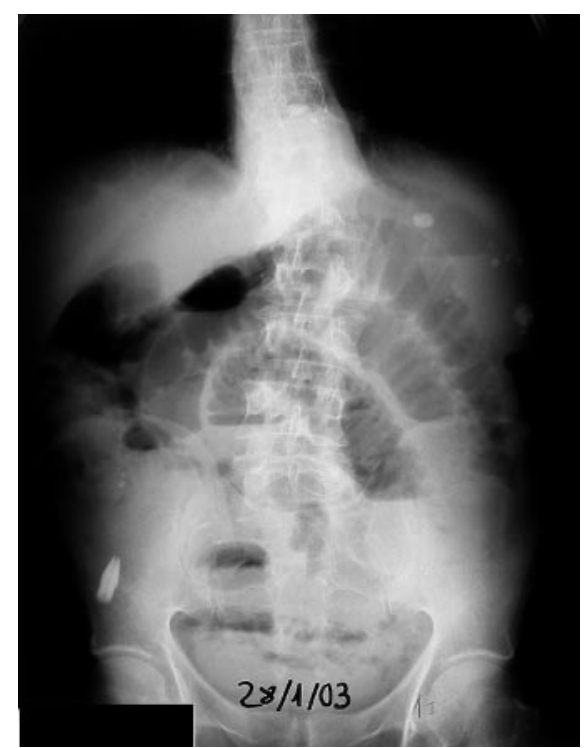

Figure 1 Plain abdominal radiograph showing distended small-bowel loops and the olive tip of the delivery device located in the ileocecal valve area. deployment has been completed, to facilitate removal of the delivery device.

The patient had severe abdominal pain with marked abdominal distension 24 hours after stent placement. Physical examination revealed abdominal tenderness without peritoneal signs and increased peristalsis. Plain abdominal radiographs showed distended smallbowel loops and the olive tip of the delivery device in the right lower quadrant, presumably obstructing the ileocecal valve (Figure 1). A computed tomography (CT) scan confirmed the obstruction of the ileocecal valve by the olive tip (Figure 2). A nasogastric tube was placed through the esophageal stent to decompress the gastrointestinal tract, and conservative treatment was indicated initially. Clinical improvement was remarkable within 12 hours. Further plain abdominal radiographs demonstrated the passage of the olive tip to the right colon and decompression of the small bowel. The patient was discharged 24 hours later, completely asymptomatic and on a soft diet.

This complication has not been previously reported $[4,5]$. The olive tip should pass along the alimentary tract without causing symptoms as most foreign objects do. We routinely use this type of stent, with excellent results with regard to relief of dysphagia, and we have encountered no

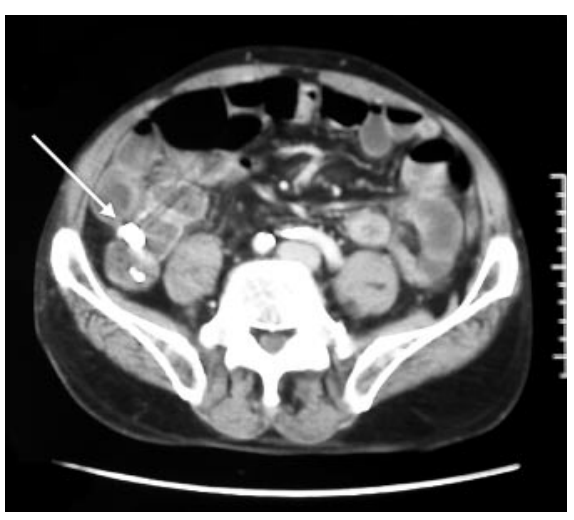

Figure 2 Computed tomography (CT) scan confirming ileocecal valve obstruction by the olive tip (arrow). other complication of this kind. We speculate that the patient may have an ileocecal valve abnormality. Since the patient's condition at present does not justify any further diagnostic procedures, this can only be checked in future at necropsy.

\section{F. J. Jiménez-Pérez, J. Vila,}

M. Iñarrairaegui, D. Carral, F. Borda

Endoscopy Unit, Hospital de Navarra,

Pamplona, Spain.

\section{References}

${ }^{1}$ Cwikiel W, Tranberg KG, Cwikiel M et al. Malignant dysphagia: palliation with esophageal stents - long term results in 100 patients. Radiology 1998; 207: $513-518$

${ }^{2}$ Moses FM, Wong RK. Stents for esophageal disease. Curr Treat Options Gastroenterol 2002; 5: 63-71

${ }^{3}$ Siersema PD, Marcon N, Vakil N. Metal stents for tumors of the distal esophagus and gastric cardia. Endoscopy 2003; 35: 79-85

${ }^{4}$ Song HY, Jung HY, Park SI et al. Covered retrievable expandable nitinol stents in patients with benign esophageal strictures: initial experience. Radiology 2000; 217: $551-557$

${ }^{5}$ Shim CS, Cho YD, Moon JH et al. Fixation of a modified covered esophageal stent: its clinical usefulness for preventing stent migration. Endoscopy 2001; 33: $843-848$

Corresponding Author

\section{F. J. Jiménez-Pérez, M.D.}

c/ Harizti 41

31892 Zuasti de Iza (Navarra)

Spain

Fax: $\quad+34-9484-22303$

E-mail: jjimenezp@retena.com 